\title{
Titanium-strip cranioplasty
}

\author{
G A S BLAIR, T F FANNIN, D S GORDON
}

\section{Summary}

Titanium strips have been used to repair skull defects when preformed metal plates are not available and simple wiring would not be enough. The technique is simple, obviates the need to dissect the dura mater, and gives greater resistance to further impact injury than an inlay technique.

\section{Introduction}

Defects of the skull usually result from comminuted depressed fractures or operations for intracranial tumour. In the repair of small defects autogenous bone grafts or acrylic plates often prove satisfactory. For larger defects, however, metal plates are more readily moulded to the skull contour and may be screwed to the surrounding bone by an onlay technique. Because of its mechanical properties, radiolucency, low specific gravity, and inertness in the tissues titanium is the most suitable metal. ${ }^{2}$ Simpson ${ }^{3}$ found no evidence of a reaction in the dura mater beneath a plate that had been in position for several years. Meachin and Williams ${ }^{4}$ showed staining on histological examination but no clinical evidence of tissue reaction to unanodised titanium.

Gordon and Blair ${ }^{2}$ described titanium cranioplasty in which plates shaped in a high-pressure hydraulic forming chamber were used. We describe how previously prepared titanium strips may be used when such equipment is not available. The strips may be used for immediate cranioplasty at the time of primary wound closure as well as for the more usual delayed cranioplasty.

\section{Materials}

Strips of titanium IMI $115,0.6-\mathrm{mm}$ thick, are cut to various widths and lengths (see table). When the edges have been dressed holes with chamfered edges are drilled at intervals along the strips. After mechanical polishing the strips are immersed for a few minutes in a pickling solution $(8 \%$ nitric acid, $1.5 \%$ hydrofluoric acid, $90.5 \%$ water) to remove any metallic contaminants and then anodised to a final anode voltage of $60 \mathrm{~V}$. This changes the surface colour from grey

Details of titanium strips, screws, and dental burrs used in cranioplasty

\begin{tabular}{|c|c|c|}
\hline $\begin{array}{l}\text { Titanium strips: } \\
\text { Widths }(\mathrm{cm}) \\
\text { Lengths }(\mathrm{cm}) \\
\text { Diameters of holes (mm) } \\
\text { Distances between centres of } \\
\text { holes }(\mathrm{cm})\end{array}$ & $\begin{array}{c}1.5 \\
4-20 \\
3 \\
2.0\end{array}$ & $\begin{array}{c}0.5 \\
4-20 \\
2 \\
0.8\end{array}$ \\
\hline $\begin{array}{l}\text { Screws: } \\
\text { Types } \\
\text { Lengths (mm) }\end{array}$ & $\begin{array}{l}\mathrm{JCH} 342 \text { (Down Bros) } \\
5,6 \text {, and } 7\end{array}$ & $\begin{array}{l}\text { GT } 464 \text { (Down Bros) } \\
5,6 \text {, and } 7\end{array}$ \\
\hline $\begin{array}{l}\text { Dental burrs: } \\
\text { Sizes }\end{array}$ & Round 8 & Round 6 \\
\hline
\end{tabular}

Department of Dental Prosthetics, Dental School, Belfast BT12 6BA

G A S BLAIR, MDS, FFD, senior lecturer and consultant

Department of Neurosurgery, Royal Victoria Hospital, Belfast BT12 6BA

T F FANNIN, MD, FRCS, senior registrar

D S GORDON, MCH, FRCS, consultant

to gold. A dark grey plate shows through hairless areas of a thin scalp. Anodising also gives the plate an enriched oxidised surface layer, which may further, reduce the risk of tissue reaction. A full range of strips, screws, and suitable instruments is stored in presterilised packs.

\section{Technique}

Fixation of unstable fracture-In the repair of depressed fractures raised bone fragments can often be wired together to restore the contour of the skull. With more extensive injuries in which pieces of bone may be missing, however, a simple wiring technique may fail to stabilise the fractured area. In such cases titanium strips have proved ideal for joining the fragments and covering defects. A strip long enough to overlie intact bone on each side of the fracture is shaped to the desired contour with the use of orthodontic pliers. With the strip placed over the fracture site holes are drilled in the intact skull and mobile fragments with a dental burr (see table). Screws just long enough to penetrate the inner table of the skull attach the strip and stabilise the fracture (fig 1). This technique is especially useful for unstable fractures involving the superior orbital margin (fig 2).

Immediate cranioplasty-Cranioplasty is sometimes performed after debridement of the wound and repair of the dura mater. The length and width of strips used depend on the size and shape of the defect (fig 3).

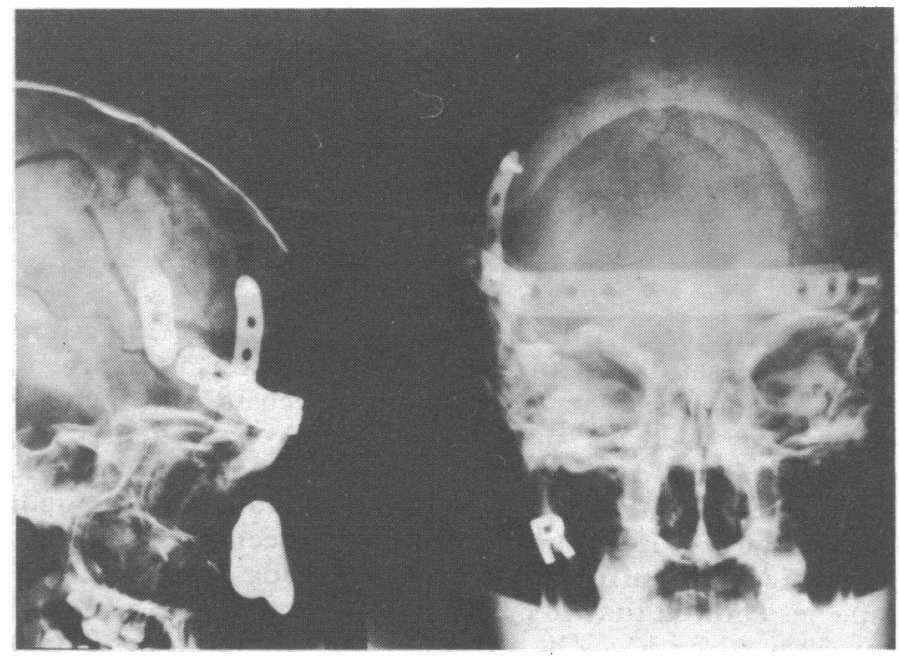

FIG 1-Titanium strips used to stabilise extensive frontal fracture with large skull defect.

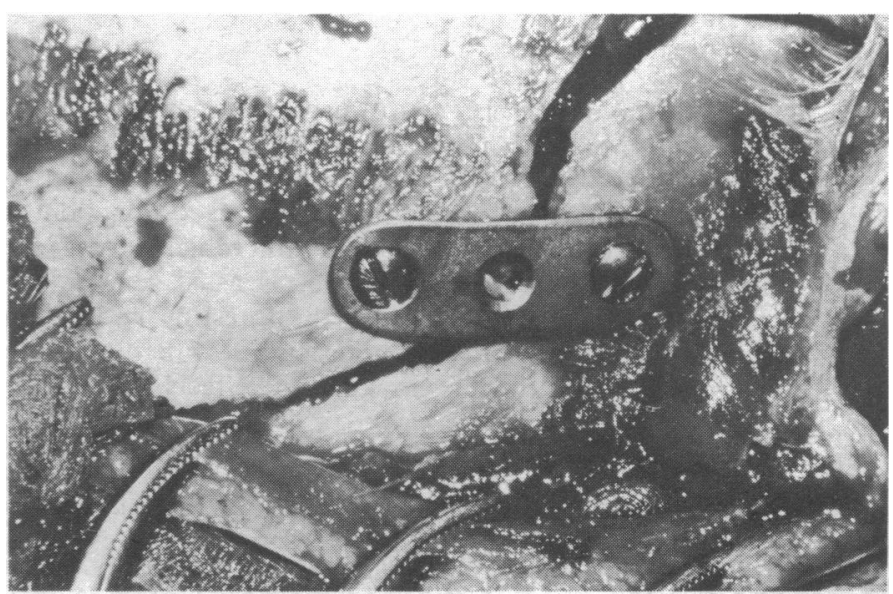

FIG 2-Short titanium strip used to stabilise mobile fracture involving superior orbital margin. 
Delayed cranioplasty-Titanium strips may sometimes be used instead of a preformed plate. If the fracture involves the frontal air inuses or mastoid air cells, however, a plate is usually preferables because it may be fixed to the skull with screws that do not penetrate areas of potential infection.

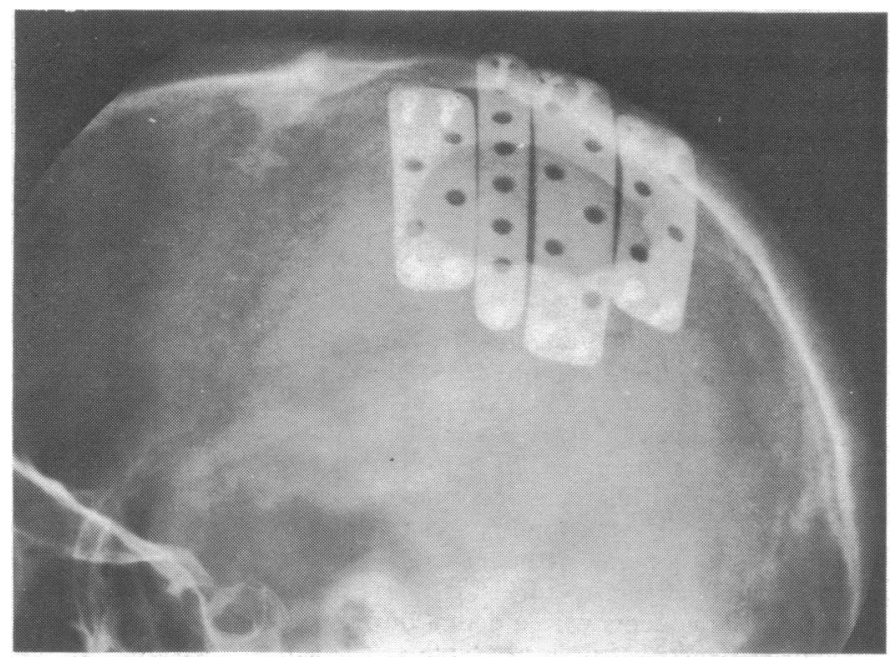

FIG 3-Titanium strips of various widths and lengths used for cranioplasty after debridement of missile wound.

\section{Comment}

Titanium-strip cranioplasty is a simple technique requiring only a dental drill, orthodontic pliers, and a basic head-injury craniotomy set. Titanium is radiolucent, which is important should contrast radiography become necessary. Its low specific gravity means that when used for large defects the patient will not be conscious of its weight. Titanium strips curved to the shape of the skull offer much greater resistance than uncontoured strips to high-impact loading. With one or two screws at each end the strips provide a strong protective cover.

This onlay technique has two chief advantages. Firstly, it obviates the need to dissect the dura mater at the margin of the defect, with consequent risk of a cerebrospinal fluid fistula or of brain damage from dissection on the undersurface of the bone. Secondly, as the strips overlie the skull for $1 \mathrm{~cm}$ or so each side of the defect, the resistance offered to further impact injury is greater than that from an inlay technique.

\section{References}

1 Simpson, D, Fournal of Neurosurgery, 1965, 22, 292.

2 Gordon, D S, and Blair, G A S, British Medical fournal, 1974, 2, 478.

3 Simpson, D, personal communication, 1976.

4 Meachin, G, and Williams, D F, fournal of Biomedical Materials Research, 1973, 7, 555.

\title{
Treatment of candidal urinary tract infection with nifuratel
}

\author{
R N GRÜNEBERG, ANNE LEAKEY
}

British Medical fournal, 1976, 2, 908-910

\section{Summary}

Three patients with candidal urinary tract infections were successfully treated with oral nifuratel, a nitrofuran antimicrobial agent active against yeasts and Trichomonas as well as urinary bacterial pathogens. The recommended dose is $\mathbf{4 0 0} \mathrm{mg}$ thrice daily for a week. No side effects that could be attributed to the treatment were noted. Minimum inhibitory concentration determinations for nifuratel against Candida strains of five species showed that 48 out of 59 organisms were inhibited by $50 \mathrm{mg} / 1$ or less, the three strains of Candida species eliminated from our treated patients having MICs of nifuratel in the range of $10-50 \mathrm{mg} / 1$.

\section{Introduction}

Candida species only rarely cause urinary tract infections, usually after urethral catheterisation in patients with urinary tract abnormalities who have received broad-spectrum antibiotics. The treatment of candidal urinary tract infection is difficult, partly because only a few antimicrobial agents are excreted in the urine and are active against yeasts. ${ }^{1}$

Nystatin is not well absorbed from the intestine and is too toxic for parenteral use, and amphotericin B, which may be used parenterally, is apt to cause serious side effects. The treat-

Department of Microbiology, University College Hospital, London WC1

R N GRÜNEBERG, MD, MRCPATH, consultant microbiologist ANNE LEAKEY, BSC, research technician ment of urinary tract infection caused by $C$ tropicalis with polymyxin has been described, ${ }^{2}$ but this antibiotic is not usually applicable to infections with other Candida species. Recently flucytosine has been used for these infections, but it is limited in its application because some strains of Candida ${ }^{3}$ are resistant to it and because the dosage has to be modified in those with renal impairment.

Nifuratel is a nitrofuran which is used to treat vaginal infections with Candida or Trichomonas vaginalis, the recommended application being a combination of vaginal pessaries and tablets. Since oral nifuratel is excreted in the urine and the drug was presumed to be active against yeasts it seemed appropriate to try its effect on candidal urinary tract infections.

We tested Candida strains for sensitivity to nifuratel in vitro, and report here three cases of candidal urinary tract infection treated with nifuratel.

\section{Case 1}

A 77-year-old man fell and fractured his third lumbar vertebra. No neurological abnormality was detected and he was treated with bed rest. Two days after his fall he developed a chest infection, which was treated successfully with ampicillin given for two weeks. Three urine specimens examined during treatment were normal.

Nine days after the accident he developed acute urinary retention and a urethral catheter was passed. The catheterisation was difficult and the presence of urethral stricture was suspected, especially since he gave a history of gonorrhoea in the remote past. Closed drainage of the bladder through an indwelling catheter was started. Eight days later his urine grew more than $10^{5} \mathrm{C}$ stellatoidea $/ \mathrm{ml}$, a finding confirmed on five subsequent cultures. A course of nifuratel tablets, $200 \mathrm{mg}$ three times daily for seven days was given. The catheter was removed on the fourth day of treatment. Urine cultures at the end of the course of treatment again yielded more than $10^{5} \mathrm{C}$ stellatoidea $/ \mathrm{ml}$. A second course of treatment with nifuratel, this time $400 \mathrm{mg}$ three times daily for seven days, was given. Further urine examination after this course showed no evidence of infection. Two months later his urine remained clear. 